\title{
Bilingual Speakers of English and Korean and Code Switching Practice
}

\author{
Jenna Shim ${ }^{1, *}$ \\ ${ }^{1}$ Department of Educational Studies, University of Wyoming, Laramie, WY 82071, USA \\ *Correspondence: Department of Educational Studies, University of Wyoming, Laramie, WY \\ 82071, USA. E-mail: jshim@uwyo.edu
}

Received: November 20, 2013 Accepted: December 20, 2013 Published: February 17, 2014

doi:10.5296/ije.v6i1.4591 URL: http://dx.doi.org/10.5296/ije.v6i1.4591

\begin{abstract}
The focus of this paper is to further understand the sociological tradition of language through the analysis of language alternation behaviors among bilingual speakers, namely Korean-Eng lish conversational code-switching. The paper investigates how and in what ways the code-s witches are used as a linguistic resource to accomplish particular social and communicative $f$ unctions as well as how and in what ways cultural-social meanings, such as social hierarchy, are both conditions for and reproduced in code-switches. The goal of this study is to look bey ond the boundaries of a particular communicative event and study the affordances that bring $t$ he particular code-choices to the present moment. The paper also explores, through the analys is of particular micro-events, that within the constraints and prefabrications in which each par ticipant operate, the possibility that people have of re-fabricating and re-synthesizing the preconditions that they are socialized into as they engage in an active and creative process of lan guage practices production.
\end{abstract}

Keywords: code-switching; bilingual speakers; communicative events 


\section{Introduction}

The relation between language and society is an ongoing concern in sociolinguistics, and it is now taken for granted that language practice should not be treated as an abstract category but as a socially/historically constituted and deeply contextualized phenomenon. Halliday (1975) contends that language did not develop because of one language user but because of two or more language users and because they wanted to communicate; thus, implying that communication is a social activity requiring the coordinated efforts of two or more individuals to get things done. Hence, longstanding sociolinguistic tradition argues that accounts of the language study must begin from the social-situational grounding on the language usage and practice (e.g., Gumperz, 1968, 1982; Blom \& Gumperz, 1972; Hymes, 1967, 1974, 2001), expanding beyond structural analysis of grammatical systems and eschewing the more static views of linguistic competence as an abstract potential explained by generative theory (e.g., Chomsky, 1965).

Furthermore, to say that language practice is inherently social in nature is, then, also to say that it is socially constructed; therefore, the constitutive relations between social factors and language in use are inevitable. To this end, understanding that the societal context that constructs the language practice itself is historically constructed by real individuals over time (Thompson, 1990) leads to an understanding that the society as a context and its meanings are always ideological (Todorov, 1984; Bakhtin, 1981, 1986). Bakhtin (1986) articulates that utterance is in part a product of the context of the utterance-a context that belongs to history, thus, indicating that our utterances are irreducibly heterogeneous and never neutral. Similarly, Gumperz (2001) claims that, "language is regarded as a set of rules enabling speakers to translate information from the outside world into sound (p.14). Gumperz explains that social categories are part of this outside world and though linguistic constraints operate largely below the level of consciousness, our language behavior is always enabled and constrained by outside world.

Thus, language in use, utterance, is the product of the interaction among interlocutors to accomplish social functions and negotiate social meanings at a micro-level intertwined with the whole complex macro social-historical situation in which it is embedded, thus no utterance in general can be attributed to the speaker exclusively (Bakhtin, 1981, 1986). These sociocultural and sociolinguistic views on language seem particularly educative and also true of hybrid text form (New London Group, 1996) like conversational code-switching in today's increasingly diverse and mobile world in which interactions across linguistics and cultural boundaries are multiplying.

The focus of this paper is to further understand the sociological tradition (as opposed to psychological) of language through the analysis of language alternation behaviors among bilingual speakers, namely Korean-English conversational code-switching. The paper investigates how and in what ways the code-switches are used as a linguistic resource to accomplish particular social and communicative functions as well as how and in what ways cultural-social meanings, such as social hierarchy, are both conditions for and reproduced in code-switches. Thus, through studying the micro events against macro conditions, I hope to 
look beyond the boundaries of a particular communicative event and study the affordances that bring the particular code-choices to the present moment. The paper also explores, through the analysis of particular micro-events, that within the constraints and prefabrications in which each participant operate, the possibility that people have of re-fabricating and re-synthesizing the pre-conditions that they are socialized into as they engage in an active and creative process of language practices production. Put differently, the conclusion of this paper argues that the code-switching are a form of language practices that are not only constituted and constrained by social/cultural contexts and meanings which embeds the language practice, but also constitutes, transforms and re-articulates the social/cultural contexts and meanings attached to them.

\section{Overview of the Study}

This study examines the code-switching behaviors among 6 participants in dinner table conversation interactions at a restaurant. A careful analysis of the data suggests that it is not correct to assume that code-switching occurs among all bilingual speakers on all occasions. The four-way conversation interactions among first, 1.5, and second generations of Korean Americans show that even though all speakers are competent in two languages (though at different levels), there are several factors entering into the selection of the codes, such as addressee-specific variations in language preference: i.e., none of the speakers spoke English to the chef, who is not a member of the family but is competent in English; the two second generation Korean Americans used only English between them, and the first generation grandmother only spoke Korean to her children; the chef spoke Korean to the grandmother but spoke English to the children occasionally.

In other words, the hierarchy of language varies even within the same event of a dinner conversation, and the negotiation of hierarchy of language connects to social hierarchy as well as who is present in relation to who the addressee is. In other words, the Korean social ideology of relative status has a major influence on how bilingual Korean Americans interact with one another, regardless of whether they are using Korean or English. Also, all speakers naturally choose from their linguistic repertoires, Korean and English, in a situated dynamic way. Thus, these conversational interactions become particularly interesting and illuminating locations for examining how bilinguals manipulate the two codes as social linguistic resources for specific communicative purposes that both are informed by and reproduce and transform larger social practices and purposes.

\subsection{Purpose}

The purpose of this study is to closely investigate the language/code choices among bilingual Korean-Americans in a natural setting, a dinner conversation. The first purpose of this study is to examine the code-switching behavior as a 'context-specific' and by doing so, examine how and in what ways the speakers use code-switching as linguistic resources (Blommaert, 2005) to accomplish social functions and negotiate their meanings. The second purpose of this study is to examine the social/cultural meanings and social structure that might help to 
explain speakers' switching from English to Korean and Korean to English. Here, the focus will be on how and in what ways the speakers code-switch from one language to another (or do not code-switch) in order to investigate whether their choice of codes is constrained by and thus reproduce social structure and the normativities of a particular social structure (Bommaert, 2005).

Blommaert (2005) states that, "It is the interplay between creativity and determination that accounts for the social, the cultural... communicative events-- the connection between agency and structure, or micro-events and macro-relations and patterns..." (p. 99). This paper aims to incorporate this particular argument of interplay between micro and macro by Blommaert's argument as its framework. The study carefully examines presupposed forces (social presuppositions) as well as creative forces (interactional level practices in which linguistic resources are used to accomplish social functions) in analyzing code-switching behavior among six participants; therefore, it aims to examine the social constraints on individual's choice of language and examine the relationship between micro-events and macro-conditions. Myers-Scotton (1992, p.417) also argues that both “...macro-level social forces as well as micro-level socio-pragmatic motives may determine which permissible patterns are preferred." (p. 417).

Despite the fact that there have been several significant research studies on code-switching, most have paid attention to either micro-event or macro-relation in trying to understand the patterns of the language choices among bilinguals. From this perspective, the present study intends to locate itself within a broader framework by filling a gap by studying both macro-level social forces and micro-level interactions. The ultimate findings of this study may not be particularly unique to Korean-English code-switching behavior especially given the research questions. However, the tools and processes that are necessary to derive at the key findings are unique to Korean-English code-switching. For instance, social factors such as cultural attachment of Korean American in relation to language choice and the acculturation of Korean American focusing on language (Kim, 1988) that is considered within the theoretical paradigm of adhesive adaptation (Hurh, 1984) are unique to Korean Americans and their language practices. Also, since Korean is a honorific language and English is non-honorific language, some characteristics of code choice and code-switching among interlocutors would be distinct from characteristics of code-switching between other languages, for example, between two non-honorific languages or one language with gender-specific morphemes and another without.

Also, in examining the ERIC Database for research pertaining to 'language-context' analysis type (borrowing Gee's term) of code-switching between English and Korean, I found one publication (Shin and Milroy, 2000) from 1990-2005. There was one other related publication (Martine, 1992), but it was a form-function analysis of Korean language grammar. The result was very surprising because the U.S. Census indicates that Korean-Americans are among the more recent immigrant groups to enter American society, and of the Asian and Pacific Islander population in the U.S., Koreans ranked fifth in number. 


\subsection{Research Questions}

This study intends to address three main research questions.

Research Question \#1: a) How and in what ways do the participants make use of code-switching as linguistic resources for specific communicative purpose in the particular interactional event?

Research Question \#2: How and in what ways are cultural-social meanings encoded in Korean-English code-switches?

Research Question \#3: What are the contextual presuppositions that are in play and are retrieved when the speakers code-switch (and don't code-switch)?

\section{Literature Review}

\subsection{Different Perspectives on Bilingualism and Code-Switching}

Just as research in literacy has shown changing views of teaching and learning (Alexander \& Fox, 2004), there have been changing views of research in bilingualism and code-switching. Some of these perspectives are distant from the primarily social one with which this study is concerned. For example, there exists a large body of literature on neurolinguistic and psycholinguistic aspects of bilingualism which generally address issues such as lexical storage and retrieval processes of different languages (Vaid, 1986; Hyltenstam \& Obler, 1989).

In relation to the studies in code-switching, early researchers viewed code-switching largely as a phenomenon that takes place between sentences. For example, Weinreich (1953) states that "an ideal bilingual switches from one language to the other..., but...certainly not within a single sentence" (p.73). Also, among a number of possible reasons for code-switching that Crystal (1987; cited in Skiba, 1997) presented was the notion that a speaker may not be able to express $\mathrm{him} / \mathrm{herself}$ in one language so switches to the other to compensate for the deficiency. Romaine (1995) notes that a realistic understanding of bilingualism has been hindered by the use of the term such as "the ideal bilingual" and "full bilingualism" which carry the implication that there are other kinds of bilingualism which are not ideal or full. This is also contradictory to the concept of multi-literacies (Street, 1995) as Blommaert also points out that bilingualism or multilingualism is a conditioned and enacted resource, not something one has or doesn't have.

Within the linguistic studies of bilingualism and code-switching, different emphases and approaches can also be found. Muysken and his colleagues, for instance, have been working within the framework of generative grammar and focusing on the problem of specifying structural constraints on code-switching (Muysken, 1990). Poplack and Sankoff carried out extensive work on Spanish-English code-switching data collected from New York City's Puerto Rican community (Poplack, 1980). Similar to Muysken's research, Poplack and Sankoff were interested primarily in the question of specifying structural constraints on 
code-switching, but they didn't focus on categorical constraints on code-switching. Poplack and Sankoff also investigated the difference between borrowing and code-switching. While these studies have significance in our understanding of the internal linguistic characteristics of bilingualism and code-switching, the social aspect of bilingual language choice seems to be somewhat neglected. In other words, the aspects of the networks of social and cultural relationships in which the individual interacts and which shape (and is shaped by) the way we use language have not been the focus.

\subsection{Sociolinguistic Approaches to Code-Switching}

In contrast to aforementioned researchers, Gumperz's work on bilingual discourse strategies showed that language alternation, far from constituting a language deficit, provides an additional resource which bilingual systematically exploit to express a range of social meaning. Furthermore, he found that code-switching occurs not only across sentences, but also within a single sentence (Gumperz, 1982).

The social significance of code-switching has been studied and discussed by a number of researchers. For example, Hymes (1972) states that it is normal for speakers to switch between languages or styles depending on the topic and interlocutors; he also states that "no normal person, and no normal community, is limited to a single way of speaking, to an unchanging monotony that would preclude indication of respect, insolence, mock seriousness, humor, role distance, and intimacy by switching from one mode of speech to another" (p. 38). Heller (1988) suggests that "the reason for studying code-switching is that code-switching violates the strong expectation that one language should be used at any given time" (p.1). Yet, code-switching is essentially a social phenomenon (Heller, 1988). In addition, Blom \& Gumperz (1972) have studied code-switching to find out the role of social norms in determining patterns of code-switching. To this end, code-switching is a complex communicative strategy and a particular "semiotic constellations" that mediate language and social/cultural meanings.

Within sociological research in code-switching, many researchers view an individual's choice of code or language as a product of what the speakers understand is going on around a specific interaction in a specific setting and what they take the behavior of others to mean. Several researchers, while recognizing that individual's choice of language depends on interactional level, they also affirm that an individual's choice of language is constrained by what is already presupposed by social rules. Gumperz (1982), for instance, states that social presuppositions play an important part in understanding the scope of speech variations in human interaction and he characterized. Parallel to Gumperz's point of view in relation to the social presuppositions, Wortham (2003) presents Hymes's (1972) study on the social presuppositions and consequences of language in use and points out the importance of analyzing the language in use to understand larger processes that might be occurring through the language use. Blommaert (2005) also states that, "a lot of what we observe in human communication is not a matter of freedom, choice, or creativity, but that it is constrained by normativities..." (p.99) In this regard, interactional-level (creativity) motivation and presuppositional motivation should be viewed as intertwined and must be drawn together 
when studying code-switching behavior of bilinguals.

As with any study, there are, of course, different perspectives among the primarily social studies of code-switching. In this part of the literature review, I will focus on three approaches to the study of the social functions of code-switching in order to locate this research within a wider framework:

1) Blom \& Gumperz, (1972), Gumperz, (1982), Situational and metaphorical code-switching

2) Gumperz (1982), Conversational code-switching

3) Myers-Scotton (1983), Markedness Model

\subsection{Situational and Metaphorical Code-Switching}

Blom and Gumperz (1972, p. 421) visualize the relationships between social and linguistic factors. They find that social factors restrict the selection of linguistic variables, while syntactic environments serve to narrow the broader dictionary meaning of words. In addition, Gumperz (1982) considers code-switching as a type of contextualization cue and states code-switching as "an element in a socially agreed matrix of contextualization cues and conventions used by speakers to alert addressees, in the course of ongoing interaction, to the social and situational context of the conversation" (p.132). According to Gumperz code-switching provides contextual information equivalent to that which can only be conveyed through prosody, paralinguistic signs, or other syntactic or lexical processes in monolingual settings. Blom and Gumperz differentiate between two kinds of switching: 'situational switches' and 'metaphorical switches.'

In situational switching, a language or a speech style is regularly associated with particular activities or settings and its use comes to connote them. In other words, code-switching is induced by a change in the participants or social (situation) settings or activity type. Blom \& Gumperz (1972, p.425) notes that, "the notion of situational switching assumes a direct relationship between language and social situation," and this implies that the code-switching behavior can be predicted by some kind of predetermined model and a particular normatives. Using situational switching as a lens allows me to analysis the durable and presupposed social factors that constrain the juxtaposition of the two languages.

However, not all instances of code-switching correspond to changes in situational context. Blom \& Gumerz (1972); Gumperz (1982) recognizes this fact and clarifies that speakers switch from one language (code) to another in order to achieve certain communicative effects and functions, while participants and setting remain the same. This type of linguistic behavior is referred to as metaphorical code-switching (Blom and Gumperz). According to Blom and Gumperz metaphorical switching involves a shift in contextualization cues as well as other content markers that characterize the situation, without an accompanying shift in topic. Using metaphorical switching as a lens allows one to analyze dynamic and creative individual code choices made to achieve communicative effects at the interactional level. 
Gumperz (1982) states that "what distinguishes bilinguals from their monolingual neighbors is the juxtaposition of cultural forms: the awareness that their own mode of behavior is only one of several possible modes, that style of communication affects the interpretation of what a speaker intends to communicate and ...” (p. 65). Gumperz argues that code-switching is neither random nor meaningless; therefore, the selection of codes carries social significance recognizable among interlocutors largely at the level of unconscious.

\subsection{Conversational Code-Switching}

Gumperz (1982) noticed that speakers of different languages in California sometimes use both languages while they maintain a rapid flow in their conversation. No hesitation, pauses or changes in sentence rhythm indicate the shift. He observes that speakers in these cases seem to make no distinction between an unmarked and a marked language.

According to Gumperz (1982, pp. 75-80), a specific language may be chosen to perform conversational functions, such as addressee specification, interjection, quotations, reiteration, message qualification, and personalization vs. objectification. He also finds that another function of code-switching is to make a distinction between in-group and out-group audiences. In this regard, he distinguishes between 'we' code and 'they' code. Speakers often switch to 'they' code to imply authority, dominance, and objectivity, while they switch to 'we' code to indicate privacy, intimacy, and subjectivity. Gumperz' explanation of 'we' code and 'they' code allows one to analyze the code-switching pattern in relation to the type of social relationship (distant/close) between interlocutors and investigate the extent to which code choices and code-switching are dependent on the type of group membership: in-group membership vs out-groups membership: family members vs non family members.

\subsection{The Marked-Ness Model}

Myers-Scotton (1983, p.116) notices that the norms of the society direct a speaker to use a specific language. The power of society over the individual makes selecting one language (or dialect) over the other either 'marked' and unacceptable, or 'unmarked' and normal. To formalize this distinction, Myers-Scotton proposes the 'Markedness Model' for code-switching. The Markedness Model is built on the notion of rights (that are dynamic and creative) and obligations (that are durable and resupposed) between the speakers and the addressees.

Myers-Scotton (1988) argues that rights and obligations constitute norms in society. She states that "norms determine the relative markedness of linguistic code for a particular exchange...speakers are free to make any choice, but how their choice will be interpreted is not free" (p.155).

The Markedness Model does not restrict the speaker in switching to a specific language. The speakers are free to choose their own code; but the norms of the society determine the perceived acceptability of the code chosen in any given case. Each conversational setting has its own rights and obligations, and the interlocutors are expected to behave accordingly. The Markedness Model provides a framework through which I can microscopically investigate the code-switching speech behavior in relations to its social indexicalities. 
In order to gain a deeper understanding of both distal and immediate social contributing forces in the complex and dynamic context of Korean-American interactions, the next section provides a brief overview Koreans. It provides an overview of the history of Korean immigration to the United States, Koreans, Korean culture and Korean language in relation to social structure. I also discuss how social hierarchical structure is encoded in the language as well as discussing "ethnic attachment" and "adhesive adaptation" of Koreans and their lives in America. The following literatures are reviewed understand beyond a basic assumption that the code-switching is a linguistic system. Complementing the perspectives of other scholars already mentioned above, Halliday claimed that 'the linguistic system is a sociolinguistic system' (1978, p.72). I aim to understand these relations among speaker, the language and social system.

\section{Koreans in America}

Korean Americans are one of the fastest growing ethnic groups in the United States. The 2000 Census counted 1, 076,872 Korean Americans, up from 798,849 in 1990 and 70,000 in 1970. The 2000 Census also recorded an additional 151,555 Americans of part-Korean ancestry.

Despite the fact that the history of Korean immigration goes back as far as to 1903 (Hurh, 1998), recognition of Korean immigrants as distinct Asian American group in the United States is quiet recent. Until the late 1970s, public awareness and interest in Korean American were minimal; in fact, it was not until the 1970 census that Korean Americans were recognized separately from "other Asians." (Kim, 1988).

A few years following the 1965 Immigration and Naturalization Act, the most liberal immigration law in American history (Byun, 1990), the economic trading has become more active between Korea and the United States, thus, Korea and Koreans have entered the American consciousness. Although Korean Americans share many similar cultural characteristics with other Asian Americans, the Korean Americans are unique in terms of their strong ethnic attachment, extensive participation in Christian churches, heavy involvement in self-employed small businesses, wide geographic dispersion in settlement, and the emergence of the 1.5 generation phenomenon (Hurh, 1998). In the following sections, I first discuss the use of honorifics in Korean language followed by ethnic and cultural attachment of Korean American: "adhesive" adaptation in relation to the acculturation of Korean Americans.

\subsection{Koreans, Culture, and Language}

Confucianism entered Korea in the early period of the Three Kingdoms (57 B.C.-A.C.688), and its values and ethics eventually became the core of the Korean national character, particularly during the Yi dynasty (1392-1910), (Hurh, 1998). The doctrines of Confucianism center upon: 1) ancestor worship and 2) Filial piety - devotion and obedience to and reverence of the elders of the family by the younger members. On Confucianism, the ultimate goal is individual happiness, and it is believed that the necessary condition to achieve 
happiness is through peace. Among a few principles toward peace consisting of relationships that are based on love and duties are the gentlemanly man of virtue and the proper playing of society's roles. Therefore, the harmony between social order and each individual were thought to be one of the keys to the ultimate goal of human happiness (Phillips \& Eui-Young, 1982).

Over time, Confucianism values became a model for social value and order, dictating morals and ethical norms although very few Koreans identify their religious faith with Confucianism today. The basic concepts of Confucian ethics govern interpersonal relations and emphasis of relative status. One is always more powerful, older, higher or lower in rank than the other. Stretching beyond the circle of family members, the respect for age, status, and rank is stressed in, and governs, social interactions in order to maintain integrity and honor for oneself and one's group. These Confucianism values permeate every aspect of Korean culture, including the life of Korean immigrants in the United States, who are largely Christian. In short, Confucian values have become the "collective unconscious" of the Korean people (Kwon, 1995).

The importance of relative status in Korean culture has implications for how social interactions are conducted. In other words, relative status must first be known in order for a conversation to be conducted with the assurance that the correct linguistic forms are adopted by each participant with respect to the other participants. This is why it is not uncommon for a stranger to ask for another person's age among Koreans. Put differently, Korean is a honorific language in which any form of talk by speakers of Korean reflects an adherence to a norm that is not only socially prescribed, but also linguistically encoded, and no utterance in Korean can be neutral with respect to the social context. A Korean speaker cannot avoid conveying the relationship among the addressees, the referents, and himself or herself. Thus, as Klopf and Park $(1982,40)$ stated, "The talk is structured according to social hierarchies."

\subsection{Ethnic Attachment}

The attitudes and opinions of Korean Americans about Korean cultural and ethnic traits were conducted through a study by Kim, Sawdey and Meihodfer (1980). The findings of this study show Korean American parents showed a strong desire that their children retain Korean cultural and ethnic traits, and $99 \%$ of Korean American parents wanted their children to speak only Korean at home. The findings also show that over $90 \%$ of Korean American parents wanted their children to learn about Korean culture for their own self identity, as well as to demonstrate such Korean cultural traits as 'respecting parents,' 'being modest,' 'saving face,' and placing family needs and duties above individual interest.'

The participants in Kim, Sawdey and Meihodfer's study (1980) also expressed the seemingly contradictory responses which the researchers state as "fairly representative of the attitudes of the Korean American community in general." While at the same time the participants, Korean parents, wanted their children to retain Korean ethnic and cultural traits, they also wanted their children to adopt American cultural traits such as 'social assertiveness,' and 'developing individuality.' 
Kim, Sawdey and Meihodfer concluded that within the Korean American household, language retention and acquisition are often significant issues between parent and child. This is mainly because Korean American parents want their children to excel in school and that they are aware that their children must have strong English skills to achieve academic success in America. In meantime, they also want their children retain full use of Korean as their language of social intercourse in the Korean American home and community.

\subsection{Adhesive Adaptation}

One explanation of the findings of Kim, Sawdey and Meihodfer's study can be located within the theoretical paradigm advanced by Hurh and Kim (1984). They state that the acculturation of Korean immigrants as a visibly different racial minority is an "adhesive" or additive adaptation:

...adhesive adaptation is one of the major types of ethnic adaptation in which certain aspects of the new culture and social relations with members of the host society are added on to the immigrants' traditional culture and social networks, without replacing or modifying any significant part of the old...For example, Korean immigrants' progressive Americanization and their strong ethnic attachment are not mutually exclusive. (Hurh and Kim 1984, p. 162).

As Hurh and Kim (1984) have noted, the responses of the Korean American parents in Kim, Sawdey and Meihodfer's study can be explained by a "paradigm of adhesion," in which elements from both cultures are added together and retained rather than having one aspect replace the other. In the case of language, this may mean that Korean Americans (the first generation immigrants in particular) will learn English only for functional purpose, while retaining Korean for all or nearly all social purposes among Korean Americans (Kim, 1988).

\section{Methodology}

\subsection{Participants}

\subsubsection{Context, participants and data collection}

This study examined data from natural conversations among six Korean American participant s. A dinner table conversation was audio-taped on October 15, 2010. The conversation took it s place at a Japanese Hibachi style restaurant where the chef cooks in front of customers at th eir tables. Approximately 60 minutes of conversation was recorded, and the participants used the language of daily conversation. Background information about participants is as follows, and each category has been included to examine how speakers utilize, consciously or unconsc iously, internalized social presupposition in their conversation relating to each category amon gst their group. 
Table 1. The Participants' Demographic Data

\begin{tabular}{|c|c|c|c|c|}
\hline Name & $\begin{array}{l}\text { Relations to Kim } \\
\text { (grandmother) }\end{array}$ & Age & Bilingual Ability & $\begin{array}{l}\text { Years spent in } \\
\text { the U.S. }\end{array}$ \\
\hline Kim & Self & 59 & $\begin{array}{l}\text { Bilingual } \\
\text { Korean-Dominant }\end{array}$ & 34 \\
\hline Helen & Daughter & 41 & $\begin{array}{l}\text { Competent } \\
\text { bilingual }\end{array}$ & 34 \\
\hline Alex & Son & 25 & $\begin{array}{l}\text { Competent } \\
\text { bilingual }\end{array}$ & 25 \\
\hline Josh & grandson & 18 & $\begin{array}{l}\text { Competent } \\
\text { bilingual } \\
\text { English-Dominant }\end{array}$ & 18 \\
\hline David & Grandson & 15 & $\begin{array}{l}\text { Competent } \\
\text { bilingual } \\
\text { English-Dominant }\end{array}$ & 15 \\
\hline Lim & Chef & 50 & $\begin{array}{l}\text { Bilingual } \\
\text { Korean-Dominant }\end{array}$ & 6 \\
\hline
\end{tabular}

Some features of this research and its processes are as follows:

1) I was interested in studying and analyzing the Korean and English code-switches in natural everyday interactions.

2) I was interested in finding out the social functions of code-switches between English and Korean.

3) I was qualified to conduct this study because I have knowledge of both languages and both cultures, in addition to my position as a student in ERDG 715 that allowed me the opportunity to gain deeper insights into sociolinguistic theories on code-switching.

4) The data was transcribed by using a standard-tape recorder.

\subsection{Transcription Procedure}

The transcription of data went through four stages: the first stage was handwriting the entire audio-recorded data; I then highlighted the incidents of code-switching to distinguish when the participants code-switch and when they don't code-switch. Next, I underlined each of the languages with different colored pens so I could easily recognize the variety of combinations of the two languages in contact. I finally translated the parts of the transcription in which the participants used Korean into English. I provided the actual intended meaning in English rather than the literal translation. 


\subsection{Data Analysis}

After transcribing the data from the tapes, I analyzed the data according to the three guiding research questions already mentioned in section 1-4 which are repeated here for clarification and convenience:

Research Question \#1: a) How and in what ways do the participants make use of code-switching as linguistic resources for specific communicative purpose in the particular interactional event?

Research Question \#2: How and in what ways cultural-social meanings are encoded in Korean-English code-switches?

Research Question \#3: What are the contextual presuppositions that are in play and retrieved when the speakers code-switch (and don't code-switch)?

The overall data analysis is motivated by Blommaert's (2005) commitment that identified the complexity of linguistic means and communicative skills as aspects of resources. The analysi $\mathrm{s}$ situates itself within sociolinguistic theories which emphasize choice and selection as basic to human communication to gain further understanding in "what people do with language and what language does to them" (Blommaert, 2005). Using Blommaert's argument of linguistic means as a resource, I used Blom and Gumperz' approaches: 'situational' and 'metaphorical' code-switching, and 'conversation code-switching. I also used Myers-Scotton, 'Markedness Model' incorporated with Hurh and Kim's 'adehesive" adaptation approach to study both 'ma cro-level' social forces and 'micro- events.' The concepts of 'macro-level' social forces and ' micro-events' have also been adopted from Blommaert (2005, p. 99) and the study will attem pt to affirm how the two forces are intertwined. Thus, the assemblage of the three frameworks , "Situational" code-switching, "Metaphorical" code-switching, and "Markedness Model" are used to analyze the factors that would account for the code choices in specific situations.

\section{Results}

The results of the data analysis first present how the participants make use of code-switching as a linguistic resource for their communicative purpose and also present what kind of communicative purposes are exchanged among participants. Then the study examines how the speakers' choice is of codes is a series of individual choices made under social constraints. In other words, there are both micro-factors that explain how the participants use code-switching as a linguistic resources to achieve the social functions in ongoing interactional processes, but the choice is constrained by the 'macro-level' social forces that explain the language choices of the participants in the study is governed by the social structures. Seen in this light, the macro-level makes visible what is presupposed and how social presupposition affect the language choice. In doing so, I hope to demonstrate the relationship between macro level conditions and micro level code-switching processes.

Furthermore, once data was transcribed, it became apparent that code-switching occurred only between certain speakers which implies that the speakers knew what the preferred 
language is for an ongoing interaction and the code choices among the participants display sensitivity to social hierarchies: older vs. younger; in-group member vs out-group member. Also, the participants juxtaposed the codes in order to draw the attention of addresses to some specific discourse structure (Gumperz, 1982).

\subsection{Micro-Event: Code-Switching as a Linguistic Resource in the Specific Event}

Gumperz stated that code-switching provides contextual information or contextual cues. The following sections will examine what kinds of "contextual information or cues" are being exchanged among speakers and how the speakers use code-switching as a linguistic resource for their communicative purposes and social functions. All three frameworks aforementioned will be integrated; however, the analysis on the interactional level will be the primary focus of this section, and then in the following section, the micro-event's relation to the larger social meanings (macro conditions) will be discussed.

\subsection{Code-switching as contextualizing turn-taking}

Sacks, Schegloff and Jefferson (1974) cited in Jaworski and Coupland (1999), suggest a list of guiding principles for an organization of turn-taking in conversation. According to Sacks, Schegloff and Jefferson, turn taking is facilitated by variation of certain features such as pitch, pitch, volume adjacency pair and other features such as tempo by lengthening the last syllable of use stereotyped tags. (Jaworski and Coupland, 1999, pp. 20-21). Meanwhile, Gumperz (1982) suggested that code-switching provides contextual information equivalent to that which can only be conveyed through prosody, paralinguistic signs, or other syntactic or lexical processes in monolingual settings

The following sequence shows how the participants use code-switching to contextualize turn transition much as monolinguals use prosodic cues, i.e., changes in pitch, tempo, etc, in signaling turn taking.

Sequence 1:

(1) (Helen and Alex are speaking. Josh and David are also speaking at the same time in the back ground but have been omitted in this analysis)

\section{A: ...저녁만 먹는데 무슨 perfume 을 그렇게 많이 뿌렸어? (.)}

(We just came out to eat dinner. Why are you wearing so much perfume?)

\section{H: Humm? (.) 조금 밖에 안 뿌렸어. 금새 뿌려서 그래 (.)}

(I only put a little. It's because I just sprayed it)

3. H: ((laugh)) ... 머리 아파? (.) Is it annoying?

(Does the perfume giving you a headache?)

4. A: No, no, no, which one is that? 그때 샀던 Dior 이야? 
(Is that the one you bought a while ago? Dior?)

\section{H: No, it's Estee Lauder}

In turn 2, Helen expects Alex to speak marked by the pause, but after waiting a few seconds and marked by a laugh Helen takes a second opportunity to gain the floor. She continues her turn by asking Alex a question in Korean and by doing so, Helen is positioning Alex to take the turn. (turn 3) However, when Alex didn't provide a reply Helen switches from Korean to English and asks if the smell of her perfume is annoying (turn 3). Here, Helen's code-switching specifically marks the selection of Alex as the next turn speaker, and turn transition is subsequently accomplished when Alex gives reply to Helen's question.

Helen's code-switching is said to function as a procedure for addressee specification (Gumperz, 1982). It can also be said to function as procedure for reiteration (Gumperz, 1982) because even though Helen is not repeating herself identically in turn 3 when she code-switches from Korean to English, she is communicating the similar message by emphasizing her question to mark Alex as the next turn speaker In other words, Helen uses addressee specification and reiteration strategies (Gumperz) to signal turn handovers in a manner that may be similar to prosodic cues in monolingual conversation.

What's also interesting between turns 2 and 3, Alex is not taking the turn which encodes Helen's relative status as his older sister. Alex's particular choice of the pause here can be affected by the essential part of linguistic and communicative competence for the speakers of the Korean language, in which the older interlocutors always have the priority to speak.

Sequence 2:

Helen and Alex are having a conversation about Alex's school. (Alex is a graduate student and lives out of town)

1. H: Do you have more to study?

2. A: $\uparrow$ Oh, yeah, I have a lots and lots to read...and... I still have to drive home

진짜 (.)

(really)

3. H: I feel for you. 불쌍해라... 죽겠지?

( Poor baby...you must be dying)

\section{A: Um Humm}

In this sequence, both speakers code-switch at end of their turn and the other speaker seem to naturally pick up other speaker's use of code-switching as a cue to contextualize turn handovers. In turn 2, Alex code-switches at the end of the turn and says "really." In monolingual English conversation, this doesn't necessarily mark the other person as the next turn speaker and more information may be expected after uttering the word "really." However, here the language switch marks the end of the current speaker's turn and the selection of the next turn speaker. Helen accepts Alex's cue and turn transition is completed. Schegloff's 
argument cited in Jaworski \& Coupland (1999, pp. 52-53) states that specific patterns of turn-taking could be 'evidenced' by many "markers of selective attention or perceived salience." In this sequence the patterns of turn-taking is marked by the speakers use of code-switching. Jaworski and Coupland (1999) states that “...meaning is 'located' not so much in language itself as in the interaction between language used and the circumstances of use.” (p. 52) In turn 3, when Helen code-switches to Korean, the first remark, "poor baby," expressed in Korean, positions her as an older sister and Alex as the younger one. This is very difficult to explain precisely here because the translation of the phrase "poor baby," though it comes close to what it actually means, it has a different connotation and referential meaning in Korean. Keeping in mind that the Korean language inherently conveys the relationship among the addresses, this particular remark in turn 3 is the phrase in Korean that only the older person would use toward the younger one but almost never vice versa.

Sequence 3:

While the two sequences above are examples of conversation between two people, the following sequence is an example of conversation among all six speakers. As conversation continues, the chef arrives to their table and joins the conversation while he cooks. The chef, Lim, and the grandmother, Kim go to the same church.

1. Josh: 할머니 내일 church 가?

(Grandmother, are you going to church tomorrow?)

\section{Kim: 왜? 너도 내일 할머니랑 같이 갈래?}

(Why? Would you like to go with me?)

Lim, the chef comes to the table.

3. Kim: How are you? (to Mr. Lim).

4. Lim: 안녕하셨어요?

(How have you been?)

Everyone continuing the conversation

5. Alex: [You are not going, are you?] (to Josh)

6. Josh: 거기 있는 애들 영어도 해?

(Do the kids over there speak English?)

7. Kim: 그럼, 거기 있는 애들은 거의 너 같은 애들이야

(Of course, most of the kids over there are kids like you)

8. Alex: [Give me a break, Josh ? Church?

너 안 갈거쟎아, am I no right?

(You are not going to go) 
9. Josh: Depends... 여자애들도 많이 있어?

(are there many girls?)

10. Lim: Do you like girls?

11. David: 내, 이쁜 여자만요.

(Yes, only pretty girls)

12. Josh: Shut up, Dave

13. Kim: [[니네학교 여자애들도 있는거 같더라 우리 Josh도 이제 좀 놀아야지

(There seems to be girls from your school in the church. It's time for our Josh to have some fun now)

14. Helen:=What do you mean mom? He's been 놀아ing all these times. 그치?

(right?)

15. David: That::’s $\uparrow$ right, Josh.

16. Lim: 동생이 형을 도와줘야지 Right?

(The brother should support his brother)

17. David: 괜::친아요.

(That::'s okay)

18. Josh: Hey, I'll talk you later, dude. 그래서 교회에 이쁜 여자애들 많이 있어?

(So, are many pretty girls at the church?)

19. Kim: Helen 너는 애들을 좀 풀어주는게 어떻겠니?

(Why don't you try to be more lenient for your children?)

In this multi party conversation, speakers use code-switching as their resource to retain or give up the floor. The speakers use addressee specification (Gumperz, 1982) and to mark the selection of a specific person as the next turn speaker. What is notable in this sequence are the different choices of language by different speakers depending on their addressee. In other words, some speakers only use one code or respond in one code to a specific addressee, and the factors that determine the code choices are not only immediate but also distal forces that are related to Korean culture and ethical values. However, this issue will be revisited later to examine the socio-cultural meaning or forces being contextualized by the speaker. At the moment, the aspects of code-switching as a functional resource to signal turn taking and the next turn speaker will be discussed only.

In turn 3, Alex uses the contrasting choice of language to try to compete in turn taking. In 
turn 1 and 2, the choice of language between Josh and Kim is Korean, but in turn 3, Alex tries to interrupt Kim by switching the ongoing code. However, Alex fails getting the response as Josh, in turn 4, continues to use Korean and, without explicitly selecting the next turn speaker, Josh asks a question, in Korean, to mark Kim as the next turn speaker.

In turn 6, Alex tries again to gain the floor by interrupting Kim, while he code-switches to contrasting code from Kim, but this time he adds "am I not right?" as a marker that functions as a confirmation and as a "tag-switching" (Poplack, 1980) to mark his turn completion. In turn 7 as Josh briefly responds to Alex, turn transition is achieved. Here, Alex's tag-switching marks the end of the current speaker's turn and the selection of the next turn speaker (Poplack, 1980). Similar incidents can be seen in turn 17, where Helen also uses a "tag-switching," but in contrast to Alex, she switched from English to Korean. What's also interesting is that she used a contrasting code just to highlight the key verb, "play" in Korean and adds English morpheme. Although this is interesting phenomenon, it will not be discussed here due to the scope of this paper. In turn 14, Lim uses a "tag-switching" again to mark the end of his turn.

These examples show that the language choice becomes meaningful with reference to the language used in preceding and following utterances. The speakers code-switch to contextualize and mark turn transition by contrastive choices of code.

\subsection{Code-switching as contextualizing emphasis and clarification: casual remark/personal feeling}

Gumperz (1982) states that a message in one code is repeated in the other code and the repetition serve to clarify, amplify or emphasize a message. However, Gumerpz (1982, p.93) states that "code-switching is more than simply a way of contrastively emphasizing part of a message."

Sequence 4

Helen is directing her utterance toward her children.

1. H: Are you eating your vegetables? (.)

2. H: You guys, 야채 꼭먹어야돼

(must eat your vegetables)

3. J: I am eating them

4. D: Me too

In this sequence either Josh or David replies to Helen, and she switches from English to Korean to reiterate and amplify her question. Her question is not reiterated identically but in "somewhat modified form" (Gumperz). Helen's comment on turn 2 is understood both by Josh and David as an reinforcement of Helen's question in turn 1; therefore, rather than 
directly responding to Helen's comment on turn 2, but Josh and David answers Helen's question in turn 1. However, framing within Gumperz's way of CS analysis, there seems to be more to this example than just emphasis of the question in turn 1. Gumperz (1982) provides a similar example as above:

Situation: A father was talking to his 5-year-old son, who was walking ahead of him through a train compartment and wavering from side to side. Keep straight. Sidha jao (Keep straight) (EnglishHindi-Gumperz, 1982, p.91, [57a]).

This analysis was corroborated by other Hindi-English bilinguals who were presented with this example (Gumperz, 1982, p.92). However, if the speaker switched from Hindi to English, these bilinguals perceived the item as "a mild threat." Gumperz (1982, p.92) suggests that these meanings are associated with the relative status and social functions of Hindi and English within the bilingual community in the language of family, peers, and solidarity, whereas English is the language of work, power and formal social functions. Correspondingly, utterance in Hindi tend to sound more "personalized," "subjective," and "involved" whereas those in English sound more "formal," "objective," and 'detached."

By switching from Korean to English, Helen's speech act became a "personal appeal." In the reverse case, it would have been a "mild threat." In other words, Helen has chosen "personal appeal" over "mild threat" to express her intention to request both Josh and David to engage in some action, which is 'to eat some vegetables.' Helen's code-switch can also be seen as exerting her authority as the mother. However, neither Josh's or David's response in turns 3 and 4 to their mother correlates with the "ethnic attachment model" or Adhesive adaptation model because both children did not speak to the family member in Korean which questions addressee-specific code-choice in relation to in-group and out-group members. This issue will be revisited later once the pattern of code-switches in relation to the aspects of distant and close relationships among interlocutors becomes visible.

\section{Code-switching as contextualizing repair}

Sequence 5

Lim, the chef, is taking the order from David.

1. L: Would you like fried rice or noodles?

2. D: Chicken 주세요

(I'll have some chicken)

3. L: I meant... 복음밥 먹을래요 아님 국수먹을래요?

(would you like fried rice or noodles?)

4. D: 복음밥이요 (I'll have some fried rice) 
In this sequence, David does not respond to Lim as normally expected (turn 2). Therefore, after some pause, Lim reiterates his question identically in contrasting code, turn 3. Here, Lim offers another opportunity for David to repair his response, and Lim this by code-switching from English to Korean. According to Gumperz (1982), repairs and corrections are marked by accent or rise in pitch and by lexicalized transitions such as "no" or "I mean" (p. 184). In turn 3, Mr. Lim does initiate his attempt to repair by saying, "I meant" but he deploys code-switching as do monolinguals would deploy prosody.

Sequence 6

Alex and Lim are exchanging a brief conversation soon after Lim is done cooking.

1. Lim: How was everything?

2. Alex: 잘 먹었습니다... 고맙습니다.

(That was good. Thank you)

3. Lim: 아직 배 안부르시죠?

(You're not full yet, aren't you?)

4. Alex: 오....내

(Oh....yes)

5. Lim: What can I get for you?

6. Alex: 배 불러요. ((touching his stomach))

(I'm full)

In this sequence, Lim is making a Korean way of courtesy remark by asking (turn 3), "You're not full yet, aren't you?" In Korean language, a negative tag question is answered by a negative in order to negate the sentence. This is opposite in English; a negative tag question is answered by a positive to negate the sentence. In other words, Alex, thinking in English, answered by positive response, "Oh, yes," in order to say that he is not "not full," to indicate that he is full. However, Lim, was expecting an answer in Korean way of responding to a tag question. By hearing Alex's response, "Oh, yes," Lim understood Alex as being "not full." Therefore, Lim's question on turn 5 offers Alex to clarify or repair his original response in turn 5. In turn 6, turn transition is achieved and Alex clarifies his response by indicating that he is full.

What's notable in the sequences 5 and 6 is that despite the fact that Lim code-switches between Korean and English, all other interlocutors speak to Lim in Korean. To this end, I now turn to a broader constitutive frame that restrict and determine the code-choices among the interlocutors. 
6.4 Macro and distal forces: the social constraints represented as functions of code-switching

In analyzing the data, it becomes evident that the contrastive choices of codes among participants are addressee-specific. The study reveals that group membership is an important factor, determining the degree of use of one language or the other. How participants utilized their code-choices as a linguistic resource in micro-processes has already been discussed in the previous section using Blom \& Gumperz' Metaphorical Switching paired with Myers-Scotton's Markedness Model as a framework. The following section examines more distal forces and "macro-forces" using Blom \& Gumperz' Situational switching to understand how the socio-cultural meanings and the hierarchy of social structure are contextualized in code-switching among the speakers.

\subsection{Different language choice patterns}

There are ample evidences of addressee-specific use of code-switching in the original transcript. However, due to the limited space, the previous examples already provided above will again be used.

Pattern one: Alex and Helen In considering Sequence 1, it is notable that both Helen and Alex code-switching back and forth within a sentence level (turn 3 and 4). This is consistent throughout other parts of transcribed data.

Pattern two: Kim and Her Children In considering Sequence 3, it is notable that Josh consistently speaks to Kim in Korean. This becomes interesting because Josh more competent in English, but revisiting the table in section 3-1, Kim has been living in the U.S. for 30 years and is a bilingual. In turn 12 Kim's daughter, Helen speaks to Kim in English but in turn 17, Kim's delayed response to Helen's remark (turn 12) is in Korean. Throughout the transcribe data, Kim only speaks Korean to her children.

Pattern three: Kim and Lim In considering Sequence 3, despite the fact that Kim speaks to Lim in English, Lim responds back to Kim in Korean. Although this pattern occurs only once in the data shown in the study, there are other sequences in the transcript that show this pattern.

Pattern four: Lim and Others In considering Sequence 3, 5 and 6, it is notable that all participants speak to Lim, the chef, in Korean regardless of Lim's choice of a code. In Sequence 3 in turn 14 and 15, Lim speaks in Korean and David responds in Korean. In turn 8 Lim asks a question in English, but in turn 9, David responds in Korean. In Sequence 5, again, Lim speaks in English but David still responds in Korean. Similarly in Sequence 6 in turns 1 and 5, Lim speaks in English but in turn 2, 4 and 6, Alex responds back in Korean.

Pattern five: Josh and David In considering Sequence 3 in turn 10, 13, and 16, it is notable that either Josh or David code-switches when directing their conversation to each other. In turn 16, Josh does code-switch in the second part of his turn, but it is directed to Kim, not David. Throughout the entire dinner conversation, Josh and David do not code-switch when conversing between themselves and their choice of language remains as English.

Pattern six: Helen and her children/ Helen and her mother In considering sequences 3 and 
4, Helen and her children alternate between Korean and English, and although Kim always uses Korean to her children, Helen uses both codes.

\section{Findings and Interpretations}

All speakers who have ability to use both languages do not always code-switch, and the speakers have preferred language choice. Drawing from the table in section 3-1, all participants, though their competency levels are different, are bilinguals. Also, Kim, Helen, Alex, Josh and David are three generations from one family and Kim and Helen have immigrated to the U.S. 34 years ago. Alex, Josh and David were born and raised in the U.S. The chef has immigrated to the U.S. six years ago. However, despite the long number of years of residency in the U.S., the language choice of the speakers is not necessarily English dominant. The choices are largely constrained and affected by the historical/cultural/social norms of the Korean society.

The results of the study suggest that the group membership is an important factor which determines the degree of use of one language or the other: the more distant the conversation partners are, the more they use Korean language during conversation. Conversely, the closer the relationship they have, the more they use English. The choice of language that all speakers (except for Kim) choose to speak to Lim (pattern 3) may be explained by Korean cultural traits as "being modest" and "respectful," particularly to people who are out-group members and are not familiar. By speaking Korean to Lim, who is an out-group member of the family, the speakers are being "respectful." Also, not speaking English to Lim meant that the speakers are being "modest." The patterns also show that the relative status among interlocutors in terms of age determines the code-choices. All interlocutors who are younger than Lim speak Korean to Lim, but the interlocutors who is older than Lim, Kim, speaks English to Lim occasionally. Also, Lim often speaks English to the interlocutors who are younger than him, but always speaks Korean to the interlocutor who is older than Lim, Kim. What is particularly interesting is that traces of the social hierarchies are found in the discourse of the second generations of Korean Americans who are not even born in Korea and are not fluent in Korean. Confucian values that entered Korea in the early period of the Three Kingdoms (57 B.C.-A.C.688), in part, still seem to operate in Korean descendants who seem so remotely distant from the Korean culture.

Also, as previously mentioned, in the Kim, Sawdey and Meihoefer's study (1980), Korean American parents showed a strong desire for their children to retain their ethnic and cultural traits. In their study, $99 \%$ of the Korean American parents spoke to their children in Korean. This seems to be the exact pattern occurring in the language choice that Kim (pattern 2) makes in this study. Kim was consistent in speaking Korean to her children and grandchildren across the conversation. Kim's code-choice seems to be addressee-specific in this regard. Another explanation of using the Korean code only to her children may be Hurh and Kim's (1984) theoretical paradigm of "adhesive" adaptation in which elements of Korean cultures are added to the new culture, and in the case of language, Kim may only speak Korean to 
in-group family members.

However, careful study of the analysis shows that the participants' code-switching behaviors not only reproduce the Korean cultural and social meanings, but they may also produce the new ones over time. For example, not all selections of codes reflected Confucian values and "ethnic attachment model" or Adhesive Adaptation paradigm. Pattern one, an example of intra-sentential code-switching, the code-switching strategy used by Helen and Alex who are in-group family members do not follow the expectation of "ethnic attachment model" because the interlocutors do not always use the Korean code. Further, although perhaps unconsciously employed, the consistent use intra-sentential code-switching strategy between Helen and Alex may be explained by Poplack's (1980) argument that their language ability, cultural values are similar and they recognize each other as members of 'more bilingual community.'

Another example that is more dynamic and demonstrates creative aspects of the code-switching behaviors is pattern five in which neither speaker code-switch to Korean at all even though they are both in-group family members. This may mean that Josh and David are no longer constrained by their mother or grandmother's expectation of retaining Korean cultural trait through the use of Korean when interacting with each other. Therefore, both Josh and David are not making further effort to communicate in Korean. When they do code-switch in conversing with Kim and Lim, their choice of language is to insert the cultural value that they consciously or unconsciously learned from either their parents or others in Korean community through media. Also in pattern six, Helen speaks to Kim in English, and Helen and her children freely code-switch from one code to the other which does not contextualize the Korean social hierarchical relationships.

\section{Conclusion}

In the present study, I investigated the code-switching patterns among Korean American bilinguals. I considered interactional level code-switching among the speakers to understand how they made the use of code-switching as a linguistic resource for specific communicative purposes. Three contextualization cues that were used by the speakers were closely examined in this study: code-switching as contextualizing turn-taking: code-switching as contextualizing emphasis and clarification: code-switching as contextualizing repair. I also considered in some detail the relationship between the social forces and language choice of the speakers. Although the individual speakers made their own choice of the codes in their interaction, their choices were constrained by the norms of Korean society. Their linguistic choices seem to conform to the Confucian values and "adhesive" adaptation paradigm (Hurh and Kim, 1984).

However, the code-switching behaviors among the participants also showed some aspects that did not conform to the Confucian values and "adhesive" adaptation paradigm which implies that the interaction at the micro level is dynamic and creative which will, over time, also constitute to new social meanings and structure. Further, the creative variance of 
code-switches among 1.5 generation and second generations showed how language practices do change in a different context. Hence, the new language practices, like the code-switches that do not obey the hierarchies of Korean social culture, can rearticulate and alter the social structure and context over time. In other words, the social meaning and language practice are crucially dependent on historical-social context but at the same time, new possibilities of the culture and its context (as well as the ideologies/social meanings within it) can be imagined as a different language practice are enacted in a different temporal and spatial context. To this extend, Halliday claims that 'with new modes of language development come new forms of knowledge' (1993, p.93). In relation to this particular study, I interpret Halliday's claim as follows: With code-switching, which is a varied (new) form of a language, comes new social forces such as ideologies and hierarchical social orders. Further, Witte (1992) points out that text (e.g.,code-switching behaviors) becomes a part context through inter-textual link. Applying this concept to this study, I interpret that the use of inter-codes (as opposed to using just one code) interacting with different social context (e.g. the U.S. opposed to Korea in a broader sense) over time can create a new social meaning and change the social structure as well as the social values within them. From this perspective, the code-switches themselves become a part of contexts through which the participants make meanings. Thus, this study attempted to reach beyond linear evolutionary characterizations of code-switches and bilingualism among Korean-Americans. Rather, the study attempted to demonstrate the enduring as well as transforming co-constitutive roles that social/cultural context and language practices occupies in the participants' lives. Further research studies that focuse on code-switching and its functions that relate to structure and agency and that look at what is encompassed beyond the surface of code-switching behavior are much needed.

\section{Discussions}

The findings of this study point to the issue of macro-sociological forces that define and determine the code choices of the participants. In other words, when the participants interact with each other, they speak within a particular "regime of language" (Kroskrity, 2000) although the effect of this probably is hardly a matter of individual choice or awareness.

Foucault (2002) discusses a historical "system of the formation and transformation of statements" which he calls "archive." According to Foucault, we cannot describe of our own archive since it is from within these rules that we speak. However, he also states that since the system operates at the lowest level by imposing normative indexical meanings to communicative events, "new rules" for the formation and transformation of statements can create "new archives." The findings of this study seem to address this aspect of "new rules" and "new archives" as the participants create the alternative norms (though they may not be aware of this effect). The importance of the concept of an archive appears to be that it helps us understand the limits within which discourse operates as well as the constraints on our choices and dynamism in discourse. Although the "political" aspect was not so much the focus of this particular paper, Foucault points out that these limits are not only historical but they are social, political and cultural. 
Moreover, Gidden's (1984) theory of structuration, where a dynamic model of the relation between structure and agency is proposed, is helpful in explaining the findings of this study. Gidden claims that actual language products stand in a dialectic relation to social structure and that linguistic-communicative event is governed by but also can be a formative of larger social processes and structures. Thus, what the participants did in terms of speaking against Korean normative standards indexes the individual agents within the larger sociological constraining forces.

Lastly, Bakthin's (1986) concept of two types of discourse, the "centripetal" and "centrifugal" forces is equally useful for this study. According to Bakhtin, there is the centripetal force or the tendency toward the norm which is embodied in authoritative discourse and the centrifugal force, or the push against authority and the imaginative space that constitutes non-static discourse. Each form of discourse presupposes particular images of knowledge, history, power and agency. In other words, where as the centripetal forces constrain what can be said and understood, the centrifugal forces suggest something about one's own subjectivity as well as about the subjectivities and conditions one confronts. According to Bakhtin, each becomes intelligible through the matrix of the other, and it is the dialogical relation between the centripetal and centrifugal forces that allow each discourse its limits, fluidity and possibilities. The dialogical relations between the centripetal and centrifugal forces in code-switching behaviors in this study were clearly evident. Further research projecting toward the code-switching as a sociolinguistic resource and how it is constituted by and constitutes the larger social structures and forces within them is needed especially in an increasingly diverse society.

\section{Limitation of the Study}

One limiting factor of this study is that the data was collected from one event. Therefore, the further study is required analyzing more data collected across several interactional events. This will allow more reliable interpretations and results. In addition, the present study recognizes the difficulty in prescribing a complete set of rules that would apply to speakers' use of one language over the other. Within this recognition, there is another limiting factor of this study. I, as a researcher, possessed limited knowledge and tools in analyzing the data at the time when the study was conducted. I acknowledge that there is much more that can be discussed in the data even within the chosen theoretical framework; therefore, I hope to develop this research further as I gains deeper insights and knowledge into the field. When readers read the conclusions drawn based on the results of this study, these limiting factors must be given consideration. 


\section{References}

Alexander, P.A., \& Fox, E. (2004). A historical perspective on reading research and practice. In R.B. Ruddell \& N.J. Unrau, (Eds). Theoretical models and processes of reading (pp.5-68). Fifth Edition. Newark, DE: International Reading Association.

Bakhtin, M.M. (1986). Speech genres and other late essays. Austin: University of Texas Press.

Berk-Seligson, S. (1986). Linguistic constraints on intra-sentential code-switching: A study of Spanish/Hebrew Bilingualism. Language in Society, 15(3), 313-348. http://dx.doi.org/10.1017/S0047404500011799

Blom J.P., \& Gumperz J.J. (1972). Social meaning in linguistic structures: Code-switching in Norway. In J.J. Gumperz \& D. Hymes (Eds.), Direction in Sociolinguistics (pp. 407-434). New York: Holt, Rinehart and Winston.

Blommaert, J. (2005) Discourse: Key topics in sociolinguistics. Cambridge: Cambridge Press. http://dx.doi.org/10.1017/CBO9780511610295

Bourdieu, P. (1991). Language and symbolic power. Cambridge: Polity.

Duranti, A. (1997). Linguistic anthropology. New York: Cambridge University Press. http://dx.doi.org/10.1017/CBO9780511810190

Foucault, M. (2002). The archaeology of knowledge. London: Routledge.

Gee, J.P. (1999). An introduction to discourse analysis theory and method. New York: Routledge.

Gumperz, J.J. (1968). The speech community. International encyclopedia of the social sciences (pp. 381-386). New York: Macmillan.

Gumperz, J.J. (1982). Discourse Strategies. Cambridge: Cambridge University Press. http://dx.doi.org/10.1017/CBO9780511611834

Halliday, M.A.K. (1975). Learning how to mean: Explorations in the development of language. London: Edward Arnold.

Halliday, M.A.K. (1978). Language as social semiotic. London: Edward Arnold.

Halliday, M.A.K. (1993). Towards a language-based theory of learning. Linguistics and Education, 5, 93-116. http://dx.doi.org/10.1016/0898-5898(93)90026-7

Hanks, W.F. (1991). Forward by William F. Hanks. In J. Lave \& E. Wenger. Situated learning: Legitimate peripheral participation (pp. 13-24). New York: Cambridge University Press. http://dx.doi.org/10.1017/CBO9780511815355.002

Hurh, W.M. (1984). Korean immigrants in America: A structural analysis of ethnic confinement and adhesive adaptation. Rutherford, NJ: FDU.

Hyltenstam, K., \& Obler, L.K. (1989). Bilingualism across the lifespan. Cambridge: 
Cambridge University Press. http://dx.doi.org/10.1017/CBO9780511611780

Hymes, D. (1972). Models of the interaction of language and social life. Code-switching in Norway. In J.J. Gumperz and D. Hymes (Eds.). Direction in Sociolinguistics (pp. 35-71). New York: Holt, Rinehart and Winston.

Hymes, D. (1996). Ethnography, Linguistics, Narrative Inequality: Toward an understanding of voice. London: Taylor and Francis.

Kroskrity, P. (2000). Regimes of language. Santa Fe: SAR Press.

Kwon, H.Y. (Ed.). (1995). Korean cultural roots: Religion and social thoughts. Chicago: center for Korean studies, North Park College.

Martin, S. E. (1992). A reference grammar of Korean: A complete guide to the grammar and history of the Korean language. Vermont: Charles E. Tuttle.

Muysken, P. (1990). Ten remarks from the perspective of grammatical theory. Strasbourg: ESF.

Myers-Scotten, C. (1993). Dueling languages: Grammatical structure in codeswitching. New York: Oxford University Press.

Myers-Scotton, C. (1992). Codeswitching as socially-motivated performances meets structurally-motivated constrains. In M. Putz (Ed.) Thirty Years of Linguistic Evolution Amsterdam (pp. 417-28). John Benjamins. Strasbourg: ESF.

Ochs, E. (1998). Culture and language development: Language acquisition and language socialization in a Samoan village. New York: Cambridge University Press.

Phillips, E.H., \& Eui-Young, Y. (Eds). (1982). Religion in Korea: Beliefs and values. Los Angeles: Center for Korean American and Korean studies, California State University.

Poplack, S. (1980). Spmetimes I'll start a sentence in Spanish Y TERMINO EN ESPANOL: Towards a typology of code-switching. Linguistics, 18, 581-618. http://dx.doi.org/10.1515/ling.1980.18.7-8.581

Romaine, S. (1995). Bilingualism ( $2^{\text {nd }}$ edition). Oxford: Blackwell.

Sacks, H., Schegloff, E., \& Jefferson, G. (1974). A simplest systematics for the organization of turn-taking in conversation. Language, 50, 696-735. http://dx.doi.org/10.2307/412243

Shin S. J., \& Milroy L. (2000). Conversational codeswitching among Korean-English bilingual children. The International Journal of Bilingualism, 4(3), 351-383. http://dx.doi.org/10.1177/13670069000040030401

Skiba R. (1997). Code Switching as a countenance of language interference. The internet TESL journal, vol. 3, 10. Retrieved November 5, 2005 from the World Wide Web: http://iteslj.org/Articles/Skiba-CodeSwitching.html

Vaid, J. (1986). Language Processing in Bilinguals: Psycholinguistic and 
Neuropsychological perspectives. Hillsdale, NJ: Lawrence Erlbaum.

Witte, S. (1992). Context, text, intertext: Toward a constructivist semiotic of writing. Written Communication, 9, 237-308. http://dx.doi.org/10.1177/0741088392009002003

Wortham \& B. Rymes, (Eds.). Linguistic anthropology of education. CT: Praeger Publisher.

\section{Appendix}

\section{Transcription Keys}

The following notations have been used in the conversation analysis for this project.

The notations are taken from Jefferson's Transcript Notation.

\section{A. Temporal and sequential relationships}

(0.0) timed intervals in tenths of a second

...speech pause

_ A short untimed pause within an utterance

\section{B. Characteristics of speech deliver}

: indicates an extension of the sound or syllables

:: more colons prolong the stretch

\section{More notations to indicate characteristics of speech delivery}

$\uparrow \downarrow$ indicates rising and falling shifts in intonation

\section{Other}

$((\quad))$ a description of some phenomenon with which the transcriptionist cannot transcribe.

\section{Copyright Disclaimer}

Copyright reserved by the author(s).

This article is an open-access article distributed under the terms and conditions of the Creative Commons Attribution license (http://creativecommons.org/licenses/by/3.0/). 